\title{
ЯЗЫКОВЫЕ СРЕДСТВА ПЕРЕДАЧИ ЭТНОКУЛЬТУРНОЙ ЛЕКСИКИ В РОМАНЕ А.С. ПУШКИНА «ЕВГЕНИЙ ОНЕГИН» (НА МАТЕРИАЛЕ ПЕРЕВОДА ДАРИО МОРЕЙРА КАСТРО АЛВЕСА НА ПОРТУГАЛЬСКИЙ ЯЗЫК)
}

\section{MEANS OF TRANSFERRING OF \\ ETHNOCULTURAL VOCABULARY IN THE NOVEL "EUGENE ONEGIN" BY A.S. PUSHKIN (BASED ON THE TRANSLATION OF DARIO MOREIRA CASTRO ALVES INTO PORTUGUESE)}

\section{Danilova}

Summary: The article is devoted to the analysis of translation of ethnocultural vocabulary into Portuguese in the novel "Eugene Onegin". The concept of realia is considered as vocabulary with national-cultural semantics of a particular culture. The purpose of the research is to analyze the ways of transferring realia in two unrelated languages and identify ethnocultural differences in lexemes, meaning similar concepts. The research methods were a contextual and comparative analysis of the realities of Russian culture in the translation of the novel, which made it possible to determine the differences in text cognition among native speakers of Russian and Portuguese. The novelty of the work lies in the analysis of Russian realia in the only translation of the novel "Eugene Onegin" into Portuguese, which was not previously the subject of research in the field of linguoculturology. It is revealed that realia are used in many areas of human activity and may contain a cultural component in the internal meaning of words and their connotations. The analysis of the main means of translation Russian realia into Portuguese is performed. The results of the research revealed differences in Russian and Portuguese realia and established language means of transferring realia into foreign languages such as correlation, hypo-hyponymic translation, assimilation, peripheral translation and calque.

Keywords: ethnocultural vocabulary, realia, linguoculturology, ethnolinguistics, comparative analysis.

\author{
Данилова Василиса Андреевна \\ Аспирант, Московский государственный \\ университет им. М.В. Ломоносова \\ vasilisa.danilovatpp@mail.ru
}

Аннотация: Настоящая статья посвящена анализу этнокультурной лексики в переводе романа А.С. Пушкина «Евгений Онегин» на португальский язык. Рассматривается термин реалия как лексика с национально-культурной семантикой, присущей определенной языковой общности. Цель данного исследования - проанализировать способы передачи реалий в двух неродственных языках и выявить этнокультурные различия лексем, означающих схожие понятия. Методами исследования послужили контекстуальный и сопоставительный анализ реалий русской культуры в переводе романа, что позволило определить различия когниции текста у носителей русского и португальского языков. Новизна работы заключается в обращении к единственному переводу романа «Евгений Онегин» на португальский язык, который ранее не являлся объектом исследования в аспекте лингвокультурологии. Выявлено, что реалии используются во многих сферах человеческой деятельности и могут содержать культурный компонент во внутреннем значении слов и их коннотации. В результате исследования были обозначены различия языковых средств передачи реалий в русском и португальском языке, и установлены способы передачи этнокультурной лексики в переводе романа, такие как корреляция, гипо-гиперонимический перевод, уподобление, перифрастический перевод и калькирование.

Ключевые слова: этнокультурная лексика, реалии, лингвокультурология, этнолингвистика, сопоставительный анализ.
$\mathrm{B}$ настоящее время большое внимание ученых уделяется вопросам, связанным с национально-культурной спецификой языка. Этнокультурные различия ярко проявляются при сопоставлении лексики двух неродственных языков, что способствует выявлению значений слов, характерных для конкретной культуры или языкового сообщества. Понимание и верная интерпретация этнокультурной лексики необходимы при изучении и преподавании иностранных языков. Данная статья посвящена анализу национально-культурной лексики в романе "Евгений Онегин" и его переводе на португальский язык с целью сопоставления компонентов значения слов и определения способов передачи реалий русской культуры XIX века на португальский язык.

Для определения культурно-маркированной лексики в ряде работ русских и зарубежных ученых используется термин «реалия». В научной литературе существует несколько определений данного понятия. В словаре лингвистических терминов О.С. Ахманова определяет 
реалии как «предметы материальной культуры, а также разнообразные факторы, изучаемые внешней лингвистикой, такие как государственное устройство данной страны, история и культура данного народа, языковые контакты носителей данного языка и т.п. с точки зрения их отражения в данном языке» [1, с. 608].

Е.М. Верещагин и В.Г. Костомаров дают следующее толкование: реалия - это культурные элементы, не имеющие соответствий в культуре обучающегося. [2, с. 34]

В данной статье термин «реалия» интерпретируется согласно определению С.И. Влахова и С.П. Флорина: реалии - слова (и словосочетания) народного языка, представляющие собой наименования предметов, понятий, явлений, характерных для географической среды, культуры, материального быта или общественно-исторических особенностей народа, нации, страны, племени и являющиеся, таким образом, носителями национального, местного или исторического колорита. [3, с. 406].

Отметим, что «понятия, которые отражают реалии, носят национальный характер и материализуются в так называемой безэквивалентной лексике», то есть не имеют полных эквивалентов в других языках [4, с. 115].

В.С. Виноградов вводит понятие «ассоциативные реалии», в которых фоновая информация отражается не в денотате, в безэквивалентной лексике, а в оттенках слова, его эмоционально-экспрессивной окраске и отдельных компонентах значения.

Ассоциативные реалии не находят вербального воплощения в безэквивалентной лексике, а выражаются в информации, которая сопровождает слово, выражение, цитату и хорошо известна носителю языка. Согласно В.С. Виноградову, реалии можно разделить на реалии-слова и ассоциативные реалии [4, с. 116].

Рассмотрим разновидности реалий русской культуры XIX века и их португальские соответствия в переводе романа «Евгений Онегин», опираясь на классификацию реалий В.С. Виноградова.

\section{Бытовые реалии:}

а) Жилище, имущество: покои - quarto, ночлег aposento, девичья - quarto de empregadas,

б) Одежда, уборы: тулуп - peles, колпак - touca, картуз - bone, фуфайка - camiseta, лапоть alparca, кафтан - pele.

в) Пища, напитки: пряник — prianik, щи — shchi , квас - kvas.

г) Единицы меры: сажень — jarda, верста — versta.

д) Музыкальные инструменты, народные танцы и песни: трепак - trepak, хоровод - jogo do prato, балалайка - balalaica. е) Народные праздники, игры: Масленица Carnaval, горелки - pega.

ж) Транспорт: почтовые - corceis de muda, тройка лошадей - troika, бричка - britskas.

1. Лексика, называющая этнографические и мифологчческие реалии:

а) Этнические и социальные общности и их представители: мужики - mujiques, казаки - cossacos.

2. Лексика, называющие реалии мира природы:

а) Реалии природы: мурава - сатро, глушь bosque inabitado, нива - campo.

3. Лексика, называющая ономастические реалии:

а) Антропонимы.

Среди антропонимов различаются общие имена и фамилии, характерные для определенной культурной общности, и индивидуальные имена, называющие литераторов, артистов, общественных и политических деятелей и прочих известных личностей. Индивидуальные имена требуют комментария при переводе на другой язык, поскольку являются прецедентными, то есть «связаны с широко известным текстом или ситуацией» и вызывают ряд ассоциаций у носителей русского языка $[5$, c. 83].

Общие имена: Дмитрий - Dmitri, Ваня - Vania, Андрюшка - Andriushka.

Прецедентные имена: Чаадаев - Tchadaiev, Истомина — Istomina, Катенин - Katenin.

б) Топонимы.

Некоторые топонимы также стоит отнести к прецедентным именам, поскольку они упоминаются в тексте не столько для обозначения конкретного географического объекта, сколько в качестве своего рода культурного знака, символа определенных качеств, исторических событий, судеб. [6, с. 284]

Милльоная - Milionnaia, Петровский замок Petrovskiy castelo, Летний сад — Letniy Sad.

4. Лексика, отражающая ассочиативные реалии:

а) Языковые аллюзии обычно содержат намек на какой-либо фразеологизм, пословицу, поговорку, крылатую фразу или ходячее выражение: приди в чертог ко мне златой - ao meu castelo de ouro vem (Строка из арии Лесты, опера «Днепровская русалка» Ф. Кауера, популярной в пушкинские времена.) [7, с. 598]; Мой дядя самых честных правил - o meu tio honesto e mui honrado («Мой дядя самых честных правил» - Иронически переиначенная строка из басни И.А. Крылова «Осел и мужик»). [7, с. 547].

б) Фразеологизмы и устойчивые выражения: поmynumь взор — ollhar deixои саі;; как Зюзя пьяный 
- ebrio; нет мочи - penoso a mim; mерзать чьюлибо душу — dar tanta emocao na alma; с корабля набал - do barco au baile.

При работе с реалиями переводчик литературного текста часто сталкивается с трудностями, что свидетельствует о проблемах понимания, когниции иностранного текста. Рассмотрим две основные трудности передачи реалий на другой язык:

1. Отсутствие в переводящем языке (ПЯ), точного соответствия переводимой реалии из-за того, что в культуре и быте, носителей языка перевода нет обозначаемого данной реалией объекта, т. е. самого референта.

2. Необходимость не только передать денотативное значение реалии, но и сохранить её национальный и исторический колорит.

В.С. Виноградов выделяет следующие способы передачи реалий на другой язык:

1. Корреляция

2. Гипо-гиперонимический перевод

3. Уподобление

4. Перифрастический

5. Калькирование [3, с. 117].

Для передачи реалий в романе «Евгений Онегин» на португальский языке используются следующие способы:

\section{1) Коррелячия}

Ведущим способом передачи реалий в романе является транскрипция с сохранением некоторых элементов транслитерации. Поскольку фонетические и графические системы языков значительно отличаются друг от друга, передача формы слова ИЯ на языке перевода всегда несколько условна и приблизительна. При первом появлении в тексте переводчик обычно сопровождает транскрибированные слова сносками или вводимыми в текст перевода объяснениями. Распространенным примером корреляции в романе является передача бытовых реалий со значением пищи и домашней утвари:

«У них на масленице жирной Водились русские блины;» "No carnaval eram de agrado Os blinis russos, sem iguais" «Им квас как воздух был потребен,»

"E o dispensável kvas chegando"

«А я так за уши драла! А я так пряником кормила!»

"As tuas orelhos te puxei! Que bons prianiks comias!»

«Заводит слово стороной О скуке жизни холостой;

Зовут соседа к самовару,»

"Ja se alegava, em tom matreiro, Do tedio que e viver solteiro; Ao samovar Lenski e chamado" Названия улиц, городов, имен собственных, фамилий также передается транслитерацией.
Например: Летний сад - Letniy Sad, Мильонная Millionnaia, Тверская - Tverskaia, Ленский — Lenski, Ювенал - Juvenal.

Достоинством транслитерации, как способа передачи безэквивалентной лексики является ее надежность. Исследователь передает звуковую оболочку транслитерируемого слова. Содержательная сторона слова раскрывается только через контекст. Тем самым удается избежать толкований нового понятия, а также связанного с этим риска неверной его интерпретации: Собранье Sobranie, Истомина — Istomina, Княжнин - Kniazhnin, Катенин - Katenin, Шаховский — Shakhovskoi.

Следует отметить недостатки, которые проявляются в транслитерации - это механическая передача безэквивалентного слова и неспособность достаточно полно раскрыть содержание нового понятия, которое может остаться либо вообще непонятым для многих получателей текста, либо будет приблизительно понято из контекста. На нашем материале к этой группе относятся лексемы, которые включены в текст без каких-либо экспликаций.

\section{2) Гипо-гиперонимический перевод}

При этом способе наблюдается редукция или увеличение семантического поля в языке перевода. В данном случае культурно-маркированная лексика передается более широким или более узким по семантическому объему, чем значения заимствования. Гипо-гиперонимический способ передачи этнокультурной лексики широко отражен в рассматриваемом переводе:

«В гостиной встреча новых лиц, Лай мосек, чмоканье девиц,»

"Aos encontroes de tao contente Estalam beijos, os cães latem"

Моська - маленькая собачка, мопс [8]. Слово передается на португальский лексемой са̃о - собака [9], которая является родовым понятием по отношению к гипониму моська.

«Весной на мураве лугов, зимой на чугуне камина,»

"Em primavera ao campo ve-lo Ou em inverno ante a lareira"

Семантическое поле сатро - поле, сельская местность значительно шире значения лексемы мурава - густая, молодая трава $[8,9]$.

«Любили круглые качели, Подблюдны песни, хоровод» "Corais, balanço, os entretiam Jogo do prato era paixão."

Подблюдные песни представляют собой особый вид обрядовых песен, исполняемых во время святочных 
гаданий [8]. В то время как в переводе используется лексема coral - песня, хор имеющая более широкое значениер [9].

«Умильно на пучок зари Они роняли слезки три;» "Dia de Graça aguavam flores Com um par de lágrimas suas dores..."

Заря, устаревшее название растения любисток, переведено гиперонимом flores - цветы $[8,9]$.

Рассматриваемый тип перевода полностью передает привычность, бытовую окраску соответствующего слова подлинника, в одних случаях придавая ему определенный оттенок, в других случаях, не внося в него никаких новых черт. Для обозначения реалии в языке перевода находится понятие, которое хоть и не совпадает с исходным вариантом, но имеет с ним значительное семантическое сходство и в известной мере способно раскрыть для получателя перевода суть описываемого явления.

\section{3) Уподобление}

При уподоблении слова называют понятия, соподчиненные по отношению к родовому понятию. Например:

«Он, правда, в туз из пистолета В пяти саженях попадал,»

"Num as com um tiro ele acertava, A doze jardas de distancia"

При переводе лексемы сажень - три аршина [8] переводчик использует аналог в португальском языке jarda, который также является мерой измерения длины, но не идентичен значению русской лексемы.

«Тут был на эпиграммы падкий, На всё сердитый господин:»

"Enamorado de epigramas, A um homen tudo aborrecia" «И заведет крещеный мир На каждой станции трактир.»

"Verao cristao nisto vantage Uma taberna, uma estalagem"

Для лексем господин и трактир переводчик также подбирает аналоги в своей лингвокультуре, тем самым следуя принципу доместикации. Ф. Шлейермахер определил доместикацию как «этноцентрическое редуцирование оригинального текста в соответствии с культурными ценностями языка перевода», т.е. как «способ репрезентации чужого нашем и непонятного текста в понятных терминах концепции принимающей культуры» $[10$, c. 50]. Таким образом, переводчик делает текст более близким и понятным носителю португальского языка.

\section{4) Перифрастический}

Нередко для передачи смысла реалии переводчик прибегает к описательному переводу. В таком случае значение слова объясняется при помощи словосочетания. Следует отметить, что перифрастический перевод особенно широко представлен в источнике.

«Зато читал Адама Смита И был глубокой эконом,»

"Mas Adam Smith ele entendia E era profundo em economia"

«Татьяну трогают; но ей Нехорошо на новоселье,»

"Comovem Tania; e bem verdade, No novo lar nao esta contente"

«Погрейся у него немножко! И в сени прямо он идет И на порог ее кладет.»

"Entra e aquece-te um instante! E porta adentro vai passando E Tania ao chao ja vai deixando"

\section{5) Калька}

В художественном переводе этот прием характерен не для передачи значений слов-реалий, то есть общеупотребительных слов в определенной национальной общности, а при воссоздании индивидуально-авторских неологизмов, когда переводчик, соперничая с автором, придумывает столь же выразительные, как в оригинале, окказиональные слова. К калькированию прибегают и при переводе пословиц и поговорок, когда в силу различных причин необходимо сохранить не только их смысл, но и их образно-смысловую основу, например:

«Капусту садит, как Гораций»

"Faz como Horacio - couves planta;"

«Как сон младенца, как луна В пустынях неба безмятежных,»

"Sono de infant, ou lua escura, A percorrer o ceu deserto" «Он возвратился и попал, Как Чацкий, с корабля на бал.»

"E como Tchatski, apenas vindo, Do barco ao baile ia subindo"

Калькирование может оказаться эффективным приемом, когда возникает необходимость передать настоящую игру слов оригинала, составляющим элементом является фразеологизм рассматриваемого типа. Калькированию пословиц и поговорок способствует то обстоятельство, которое лежит в основе этих устойчивых выражений, образы (если, конечно, они не сугубо национальные) воспроизводятся средствами языка, перевода и оказываются вполне понятными для иностранного перевода.

Однако, стоит заметить, что калькирование возможно только тогда, когда дословный перевод может довести до читателя истинное содержание всего фразеологизма (а не значения составляющих его частей). В рассматриваемом переводе автор помещает сноски и комментарии для разъяснения смысла устойчивого словосочетания, фразеологизма или поговорки.

В некоторых случаях можно наблюдать пропуск реалии, когда переводчик опускает лексему, передавая ее 
значение в контексте, либо полностью исключая в переводе. Рассмотрим такой пример:

«Летит кибитка удалая; Ямщик сидит на облучке» в переводе на португальский звучит, как "Passa a carroca, vai voando; Envolto em peles, o cocheiro".

В данном случае лексема пропущена, а значение реалии передается через контекст.

Также в строках «Пред зеркалами проводил и из уборной выходил» переводчик пропускает слово «уборная», передавая лишь общий смысл готовности Онегина к выходу. "Ficar no espelho a se burnir, Estava, então, pronto a sair".

Опущение лексем в данном материале представлено слабо, и причина обусловлена тем, что к началу XX века переводчики отказались от бытовавшего ранее свободного, вольного перевода, который допускал не только пропуск отдельных лексем и фрагментов, но и сотворчество переводчика, выражающееся в измене- нии фабулы, окончания произведения были разработаны основные понятия и концепции переводческой деятельности, в основе которых лежали эквивалентность и адекватность плана содержания и плана выражения.

Таким образом, реалия представляет собой неотъемлемую часть культуры и быта определенного народа, поэтому необходимо обращать особое внимание на способы ее передачи на другой язык. Важно также учитывать личность реципиента текста и его фоновые знания. По этой причине перед переводчиком стоит задача сохранить не только основную идею произведения, но и его национальный колорит и эмоционально экспрессивную окраску. В ходе исследования было выявлено, для передачи этнокультурной специфики лексем были использованы различные способы такие как корреляция, гипо-гиперонимический перевод, уподобление, перифрастический перевод и калькирование. В некоторых случаях наблюдается опущение реалии и передача ее смысла в контексте.

ЛИТЕРАТУРА

1. Ахманова, 0.С. Словарь лингвистических терминов / О.С. Ахманова. - Калуга, 1966. - 381 с.

2. Верещагин Е.М., Костомаров В.Г. Три типа лингвострановедческого комментария // Русский язык в национальной школе, 1972, №1, 34-36 с.

3. Виноградов В.С. Лексические вопросы перевода художественной прозы. М.: Издательство Московского университета, 1978. - 172 с.

4. Влахов С., Флорин С. Непереводимое в переводе. /Монография. - М.:Высшая школа, 1986. - 416 с.

5. Захаренко И.В., Красных В.В., Д.Б. Гудков, Д.В. Багаева. Прецедентное имя и прецедентное высказывание как символы прецедентных феноменов, 1997. - 83 с.

6. Красных В.В. Этнопсихолингвистика и лингвокультурология: курс лекций. — М.,2002. 284 с.

7. Лотман Ю.М. Роман А.С. Пушкина «Евгений Онегин»: Комментарий: Пособие для учителя // Лотман Ю. М. Пушкин: Биография писателя; Статьи и заметки, 1960-1990; «Евгений Онегин»: Комментарий. — СПб.: Искусство-СПБ, 1995. - 472-762 с.

8. Толковый словарь Ушакова онлайн [Электронный ресурс]. - Режим доступа:https://ushakovdictionary.ru/ (дата обращения: 20.01.2020).

9. Priberam dicionário [Электронный ресурс]. - Режим доступа: https://dicionario.priberam.org/dicion\%C3\%А1rio (дата 0бращения: 20.01.2020).

10. Venuti, L. The scandals of translation: toward an ethics of difference/ L.Venuti. - London: Routledge, 1998. - 210p.

(c) Данилова Василиса Андреевна (vasilisa.danilovatpp@mail.ru).

Журнал «Современная наука: актуальные проблемы теории и практики» 